\title{
An analytical method coupling Accelerated solvent Extraction and HPLC-fluorescence for the quantification of Particle-bound PAHs in Indoor Air sampled with a 3-stages Cascade Impactor
}

Céline LIAUD ${ }^{1}$, Maurice MILLET ${ }^{1}$, and Stéphane LE CALVÉ1,2,*

${ }^{1}$ Institut de Chimie pour les Procédés, l'Energie, l'Environnement et la Santé (ICPEES, UMR

7515 CNRS/Université de Strasbourg), 1 rue Blessig, 67084 Strasbourg Cedex, France

${ }^{2}$ In'Air Solutions, 1 rue Blessig, 67000 Strasbourg

\begin{abstract}
Most of Polycyclic Aromatic Hydrocarbons (PAHs) are associated to airborne particles and their health impact depends on the particle size where they are bound. This work aims to develop a high sensitive analytical technique to quantify particulate PAHs sampled with a 3-stages Cascade Impactor in order to derive simultaneously their individual concentration in $\mathrm{PM}_{1}, \mathrm{PM}_{2.5}$ and $\mathrm{PM}_{10}$.

Three key steps of the method were evaluated separately in order to avoid any PAHs loss during the global sample preparation procedure: 1) the accelerated solvent extraction of PAHs from the filter; 2) the primary concentration of the extract until $1 \mathrm{~mL}$ by means of a rotary evaporator at $45^{\circ} \mathrm{C}$ and 220 mbar and 3) the final concentration of the pre-concentrated extract to about $100-150 \mu \mathrm{L}$ under a gentle Nitrogen stream. Each recovery experiment was realized in triplicates. All these steps evaluated independently show that the overall PAHs loss, even for those with a low molecular weight, should not exceed more than a few percent. Extracts were then analyzed by using a HPLC coupled to fluorescence and Diode Array Detectors with the external standard method.

The resulting calibration curves containing between 9 and 12 points were plotted in the concentration range of $0.05-45 \mu \mathrm{g} \mathrm{L} \mathrm{L}^{-1}$ for most of the 16 US-EPA priority PAHs and were fully linear $\left(\mathrm{R}^{2}>0.999\right)$. Limits Of Quantification were in the range $0.05-0.47 \mu \mathrm{g} \mathrm{L}^{-1}$ corresponding to $0.75-7.05$

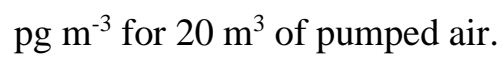

Finally, taking into account the average PAHs concentrations previously reported in typical European indoor environments, and considering the use of a 3-stages Cascade Impactor to collect simultaneously $\mathrm{PM}>10 \mu \mathrm{m}, 2.5 \mu \mathrm{m}<\mathrm{PM}<10 \mu \mathrm{m}, 1 \mu \mathrm{m}<\mathrm{PM}<2.5 \mu \mathrm{m}$ and $\mathrm{PM}_{<1}$ (and then to derive $\mathrm{PM}_{1}, \mathrm{PM}_{2.5}$ and $\mathrm{PM}_{10}$ ) for particle-bound $\mathrm{PAHs}$ quantification, the sampling duration was estimated to $20-40$ hours for a sampling flow fixed to $0.5 \mathrm{~m}^{3} \mathrm{~h}^{-1}$.
\end{abstract}

\section{Keywords}

PAHs, Cascade Impactor, Particles, Indoor Air. 


\section{Highlights}

- The final concentration of the pre-concentrated extract to about $100-150 \mu \mathrm{L}$ permits to decrease the LOQ of PAHs in indoor air.

- By using a 3-stages cascade impactor, $\mathrm{PAHs}$ bound to $\mathrm{PM}_{1}, \mathrm{PM}_{2.5}$ and $\mathrm{PM}_{10}$ can be simultaneously quantified.

- Particles PAHs quantification requires then a sampling duration of $20-40$ hours.

* Corresponding author. Fax: (0033) (0)3 688504 02. E-mail address: slecalve@unistra.fr 


\section{Introduction}

Polycyclic Aromatic Hydrocarbons (PAHs) are widespread environmental contaminants mostly formed during incomplete combustion or pyrolysis of organic material but they can also be of biogenic origin [1]. Their chemical structures contain 2 or more fused benzene rings arranged in linear, angular or in cluster structures. PAHs are ubiquitous in our environment and their emission sources are numerous: industrial processes, vehicle exhausts and domestic heating are among the major sources [2]. More than 100 of them are nowadays referenced but the American Environmental Protection Agency (US-EPA) has listed 16 among the most hazardous. One of the most famous is the Benzo[a]Pyrene $(\mathrm{B}[\mathrm{a}] \mathrm{P})$ due to its carcinogenic properties. Besides, the European ambient air legislation (directive $\mathrm{n}^{\circ}$ 2004/107/CE) targets this PAH and recommends an annual maximum guideline value of $1 \mathrm{ng} \mathrm{m}^{-3}$. Because the PAHs structures are thermally stable, most of these compounds possess high boiling point and low vapor pressure favoring their association to particulate phase in the atmosphere. The lighter PAHs (MW $\leq 202 \mathrm{~g} \mathrm{~mol}^{-1}$ ) are preferentially in the gas phase whereas the heavier ones ( $\mathrm{MW} \geq 202 \mathrm{~g} \mathrm{~mol}^{-1}$ ) are associated to particles [3-5].

Since their atmospheric concentration is relatively low (in the range of $\mathrm{pg} \mathrm{m}^{-3}-\mathrm{ng} \mathrm{m}^{-3}$ ), and especially in indoor air [6,7], the collection of airborne PAHs in vapor and particulate phases requires quite large volume of air to concentrate pollutants either on a sorbent material or on a filter. Pandey et al. (2011) reviewed sampling flow rate, for high volume samplers, in the range $2-75 \mathrm{~m}^{3} \mathrm{~h}^{-1}$ with sampling duration long enough to ensure a sufficient sampled volume of 150-900 $\mathrm{m}^{3}$ [8]. The most common sampling device is a high or low volume sampler composed of an adsorbent (XAD-2 or polyurethane foam) and a pre-filter for trapping the PAHs in the particulate phase by filtration of large air volume [9-11]. However, in the case mentioned above, the particles size is not limited. In fact, particles cause adverse respiratory health effects related to their ability to enter the lungs and potentially carrying numerous toxic compounds with them. Particle size, especially fine and ultrafine particles, is strongly related to the bad effects on human health. That's why it is of interest to focus on particle aerodynamic diameter and particle number concentrations $[12,13]$. The use of Particulate Matter (PM) sampling heads upstream the filter gives access to several cut off sizes and allow to sample particles with aerodynamic diameter $\left(D_{a e}\right)$ usually below $10 \mu \mathrm{m}, 2.5 \mu \mathrm{m}$ or $1 \mu \mathrm{m}[9,14-16]$. Other sampling systems are inertial samplers and consist to remove particles from an air stream by impaction of the particles depending on their inertia [5,17]. Particles samples collected from cascade impactors give access to more data because this device separates particles depending on their $\mathrm{D}_{\mathrm{ae}}$. Thus, physical and chemical data related to the particle sizes can be simultaneously determined to assess health effects. If further details are desired, chemical analyses may be achieved on the filters obtained in each size range. Nevertheless, despite the power of cascade impactors, to our knowledge only a few studies were conducted in indoor air with this metrology tool to quantify particlebound PAHs [5,17]. These latter were performed using a 11-stages or 3-stages cascade impactors with 
$\mathrm{D}_{\mathrm{ae}}$ in the range $0.05-18 \mu \mathrm{m}$ and $2.5-10 \mu \mathrm{m}$, respectively, which did not permit to easily compare the results on particles to those reported in the literature mentioning $\mathrm{PM}_{1}, \mathrm{PM}_{2.5}$ and $\mathrm{PM}_{10}$.

A third way to monitor particle-bound PAHs are Photoelectric Aerosol Sensors (PAS) which are analyzers using ionization principle to detect PAHs in air [18-20]. However, PAS provides a measure of the total particle-bound PAHs concentration with no distinction between individual compounds.

Several studies performed in European Environments reported particle-bound PAHs concentrations values in the range of $\mathrm{pg} \mathrm{m}^{-3}-\mathrm{ng} \mathrm{m}^{-3}$. Slezakova et al. (2009) [21] and Castro et al. (2011) [14] reported comparative values of PAHs concentrations bound to $\mathrm{PM}_{10}$ and $\mathrm{PM}_{2.5}$ in a smoking and a non-smoking site in Porto (Portugal). Castro et $a l$. found $\mathrm{B}[\mathrm{a}] \mathrm{P}$ average levels of 1.33 $\mathrm{ng} \mathrm{m}^{-3}\left(0.45 \mathrm{ng} \mathrm{m}^{-3}-2.18 \mathrm{ng} \mathrm{m}^{-3}\right)$ in the smoking place and $0.573 \mathrm{ng} \mathrm{m}^{-3}\left(0.131 \mathrm{ng} \mathrm{m}^{-3}-1.510 \mathrm{ng} \mathrm{m}^{-3}\right)$ in the non-smoking apartments used as reference. The same tendency was observed in Spain by Pey et $a l$. (2013) who studied differences in PAHs concentrations in PM $_{10}$ before and after a smoking ban in a cafeteria [22]. Fromme et al. (2004) in Germany, also studied differences in particle-bound PAHs concentration in street-side living-rooms and found median values of $0.65 \mathrm{ng} \mathrm{m}^{-3}$ for $\mathrm{B}$ [a]P in smoker's living while median value was $0.25 \mathrm{ng} \mathrm{m}^{-3}$ in non-smoker place [2]. Besides, Krugly et al. (2014) studied particulate phase PAHs in 5 schools located in urban, suburban and rural sites in Kaunas, Lithuania, and found total PAHs mean values in the range 20.3-131.1 $\mathrm{ng} \mathrm{m}^{-3}$ [4]. Sangiorgi et al. (2013) also compared levels of $\mathrm{PAHs}_{\text {in }} \mathrm{PM}_{1}$ and $\mathrm{PM}_{2.5}$ in 4 Italian offices in Milan between the cold and the warm season [23]. Again, particle-bound B[a]P sampled with Harvard impactors in homes in Amsterdam, The Netherlands, were in the range $0.49 \mathrm{ng} \mathrm{m}^{-3}\left(0.15 \mathrm{ng} \mathrm{m}^{-3}-1.12 \mathrm{ng} \mathrm{m}^{-3}\right)$ and $0.17 \mathrm{ng} \mathrm{m}^{-3}\left(0.03 \mathrm{ng} \mathrm{m}^{-3}-0.39 \mathrm{ng} \mathrm{m}^{-3}\right)$ for high-traffic and low-traffic density, respectively [7]. A last example of reported values in indoor air is the comparison of PAHs level in England where B[a]P values ranged between $0.09 \mathrm{ng} \mathrm{m}^{-3}$ (n.d. $-2.40 \mathrm{ng} \mathrm{m}^{-3}$ ), $0.09 \mathrm{ng} \mathrm{m}^{-3}$ (n.d. $-1.25 \mathrm{ng} \mathrm{m}^{-3}$ ) and $0.16 \mathrm{ng} \mathrm{m}^{-3}$ $\left(0.04 \mathrm{ng} \mathrm{m}^{-3}-0.79 \mathrm{ng} \mathrm{m}^{-3}\right)$ in 81 homes, 30 offices and 7 restaurants, respectively [6].

As demonstrated with literature values, the sampling and analysis of PAHs indoors require a high sensitive analytical method because of such low concentrations. In this study, we propose to evaluate the feasibility of using a cascade impactor to quantify particle-bound PAHs on PM > $10 \mu \mathrm{m}$, $2.5 \mu \mathrm{m}<\mathrm{PM}<10 \mu \mathrm{m}, 1 \mu \mathrm{m}<\mathrm{PM}<2.5 \mu \mathrm{m}$ and $\mathrm{PM}_{<1}$ considering PAHs concentrations reported in literature for European studies in indoor environments. This methodology requires a classical high sensitive analytical technique with concentrations step before analysis to assess low indoor PAHs level with a limited sampling volume and could be applied to simultaneously determine PAHs in $\mathrm{PM}_{1}$, $\mathrm{PM}_{2.5}$ and $\mathrm{PM}_{10}, 3$ normalized particles sizes usually reported in the literature.

\section{Materials and methods}

\subsection{Chemicals and materials}


The overall analytical procedure, including calibration curves, was performed by using a certified standard solution obtained from LGC Standards (Molsheim, France) containing the 16 USEPA priority PAHs (naphthalene NAP, acenaphtylene ACY, acenaphtene ACE, fluorene FLU, phenanthrene PHE, anthracene ANT, fluoranthene FLN, pyrene PYR, benzo[a]anthracene B[a]A, chrysene CHR, benzo[b]fluoranthene $\mathrm{B}[\mathrm{b}] \mathrm{F}$, benzo[k]fluoranthene $\mathrm{B}[\mathrm{k}] \mathrm{F}$, benzo[a]pyrene $\mathrm{B}[\mathrm{a}] \mathrm{P}$, dibenzo[a,h]anthracene $\mathrm{DB}[\mathrm{a}, \mathrm{h}] \mathrm{A}$, benzo[g,h,i]perylene $\mathrm{B}[\mathrm{g}, \mathrm{h}, \mathrm{i}] \mathrm{P}$, indeno[1,2,3-cd]pyrene IND). The initial concentration of the standard solution was $100 \mathrm{mg} \mathrm{L}^{-1}$ with $0.6 \%$ uncertainty. Solvent used was acetonitrile (Chromasolv, HPLC grade, $99.9 \%$ purity, Sigma-Aldrich) and ultrapure water was obtained from a Milli-Q water system (Millipore, St. Quentin en Yvelines, France). For recovery experiments, filters were 25 mm Glass Fiber Filter (GFF) from Pall Life Sciences (Pall Corporation, France) and Fontainebleau sand was used to reduce dead volume in extraction cells. Besides, Nitrogen (99.999\%), used for concentration step and ASE purge cycle was obtained from Messer (Puteaux, France).

\subsection{Cascade impactor theory}

The impaction theory is based on the separation of particles from the air stream by the inertial forces. A cascade impactor is the result of the assembly of several impactors arranged in series in order to collect particles of decreasing size (Figure 1a). They generally operates to remove particles of a given size range from the sample flow, either collecting them for later analysis or removing them to avoid problems of instrument contamination [24]. Different impactor designs exist such as round or rectangular impactors $[25,26]$ and this part summarizes theoretical considerations for the round impactor.

Each impactor stage is constituted of an orifice or nozzle which leads a high velocity air jet $\left(\mathrm{U}_{0}\right)$, containing particles, towards a collection plate (Figure $1 \mathrm{~b}$ ) which causes the airstream to change direction abruptly following a sharp bend $[25,27]$. Figure $1 \mathrm{~b}$ shows the air streamlines that are deflected to a sharp bend because of the collection plate. Particles which are small enough follow the streamlines and remain suspended, while those that have too much inertia impact on the plate.

The operating principle of an impactor is derived from the dimensionless Stokes number (Stk) defined as the ratio between the stopping distance of a particle and the characteristic dimension of the nozzle. Thus, considering an air flow perpendicular to a cylinder with a radius $\mathrm{R}$ (case of a circular jet impactor), the Stokes number is:

$$
S t k=\frac{\tau \cdot U_{0}}{R}
$$


where $\mathrm{U}_{0}$ is the air velocity $\left(\mathrm{cm} \mathrm{s}^{-1}\right), \mathrm{R}$ is the nozzle characteristic dimension, i.e. the radius $(\mathrm{cm})$ and $\tau$ is the aerosol relaxation time (s) which is time until the aerosol direction is changing because of the Brownian motion effect.

However, relaxation time $\tau$ is the product between the particle mass $\mathrm{m}$ and its mobility B:

$$
\tau=m \cdot B=\left(\rho \cdot \frac{\pi}{6} \cdot d_{p}^{3}\right) \cdot \frac{C_{c}}{3 \cdot \pi \cdot \mu \cdot d_{e q}}=\frac{\rho \cdot C_{c} \cdot d_{p}^{2}}{18 \cdot \mu}
$$

where $d_{p}$ is the particles' diameter, $C_{c}$ is the slip correction factor which correct differences between coarse and little particles' behavior, $\mu$ is the viscosity $\left(\mathrm{g} \mathrm{cm}^{-1} \mathrm{~s}^{-1}\right)$ and $\rho$ is the particles' density $\left(\mathrm{g} \mathrm{cm}^{-}\right.$ $1)$.

The slip correction factor, $C_{c}$ can be calculated from the mean free path of air $\lambda$, and the particle diameter [28]:

$$
C_{c}\left(d_{p}\right)=1+\left(\frac{\lambda}{d_{p}}\right) \times\left(2,514+0,800 e^{-0,55 \frac{d_{p}}{\lambda}}\right)
$$

Therefore, the Stokes number, for a nozzle diameter $\mathrm{W}=\mathrm{R} / 2$ is derived from (1) and (2):

$$
S t k=\frac{\rho \cdot C_{c} \cdot U_{0} \cdot d_{p}^{2}}{9 . \mu \cdot W}
$$

The Stokes number allows the characterization of the collection efficiency defined as the percentage of particles of a given size that are removed from the air flow by impaction. For a fixed impactor's geometry and flow condition, the Stokes number only depends on the particle properties and equation (4) shows that particle diameter is directly proportional to the square root of Stk. $\sqrt{\mathrm{Stk}_{50}}$ is often used to determine the cut size of each impactor stage which represents the particle size with a collection efficiency of $50 \%$. For most of the circular jet impactors, the number Stk $\mathrm{k}_{50}$, which corresponds to a collection efficiency of $50 \%$, takes values in the range $0.22-0.25$ [29,30]. Therefore, to collect particles with aerodynamic diameter even smaller it is necessary to increase $\mathrm{U}_{0}$ or decrease $\mathrm{W}$, i.e. R. This is achieved by varying number and/or opening diameters from one stage to the other (see figure 1a).

As shown in figure 1c, the collection efficiency can be described with efficiency curves. And the collection efficiency increases for particles larger than the cut off size and decreases for smaller particles. In addition, the nondimensional Reynolds number (Re) which describe how turbulent or laminar is the flow has an impact on the collection efficiency. Marple and Liu (1975) show that high 
Reynolds numbers (until 3000) favor the development of sharp cut size impactor whereas for low values (below 300) the sharpness of cut size is less effective [26,31].

The Reynolds number for an impactor with round nozzles is defined as:

$$
R e=\frac{\rho \cdot U_{0} \cdot W}{\mu}
$$

Even if the most important advantage of impaction technique is that aerosol parameters, size and composition, can be simultaneously established, one of the main problems stays the particle bounce effect which can occur when particles larger than the cut off diameter impact on the collection plate and then bounce and re-enter in the airstream [26]. This problem in cascade impactors is an interference because particles which have bounced can be collected on later stages and potentially contaminating the analysis. Some techniques used to reduce this effect include the use of sticky substrates [32] such as oil or porous substrates or by changing the sampling method by using a virtual impactor [24].

In our study whose results are detailed elsewhere [33], glass fiber filter systems were chosen because they are not suffering from problems of particle bounce [26]. We decided to work with a 3stage cascade impactor operating at $0.5 \mathrm{~m}^{3} \mathrm{~h}^{-1}$. Collected fractions corresponded to particles with aerodynamic diameter $\left(D_{a e}\right)$ in the ranges $D_{a e}>10 \mu \mathrm{m}, 10 \mu \mathrm{m}<\mathrm{D}_{\mathrm{ae}}<2.5 \mu \mathrm{m}, 2.5 \mu \mathrm{m}<\mathrm{D}_{\mathrm{ae}}<1 \mu \mathrm{m}$ and a final filter which permitted to collect particles with Dae $<1 \mu \mathrm{m}$.

\subsection{Analytical procedure for sample treatment}

The objective of our method is to use a cascade impactor as sampler which required to concentrate a lot the sample because this sampler, which separate particle size fractions, does not permit us to collect a lot of particles, especially in indoor air. As a consequence low LOD for the overall analytical procedure are needed. This latter consisted in a first step of extraction by means of an Accelerated Solvent Extractor (ASE 300, Dionex), a second step of concentration with a rotary evaporator and a final concentration step under a gentle nitrogen stream as described in figure 2 . All of the 3 steps were considered separately in order to evaluate the effect on PAHs losses of each step.

The overall analytical procedure was previously validated by recovery experiments using certified standard solutions of the 16 US-EPA PAHs as discussed later.

\section{ASE extraction}

Glass Fiber Filters (GFF) were placed in $34 \mathrm{~mL}$ stainless steel cells provided by Dionex (ASE 300). Fontainebleau sand was added in the cell to reduce dead space and spare solvent. In our study, 
the extraction temperature was selected based on other studies in the literature, i.e. temperature in the range $100-150{ }^{\circ} \mathrm{C}$ [34-36]. One ASE cycle consisted in a heating step of 6 min to a set point value of $120{ }^{\circ} \mathrm{C}$ and ASE pressure was fixed to 1500 psi (104 bars) for all extractions. At the end of a cycle, a nitrogen purge of $120 \mathrm{~s}$ was realized to dry all the tubing. The choice of solvent for extraction and the number of static extraction were optimized in this study as mentioned below. If necessary, the extracts were then carefully filtered through a PVDF filter $(0.45 \mu \mathrm{m}$, Restek, France).

Before use, both GFF and Fontainebleau sand were pre-cleaned with acetonitrile to remove any residual PAHs. They were stored in aluminum foil until use. Analytical blank composed of blank filters and pre-cleaned sand were also analyzed and were taken into account for quantification of samples.

\section{Concentration steps}

After extraction, the extracts (approx. $70 \mathrm{~mL}$ ) were then reduced to $1 \mathrm{~mL}$ using a rotary evaporator (Büchi) at $45{ }^{\circ} \mathrm{C}$ and 220 mbar. When necessary, a gentle stream of nitrogen was finally used to concentrate the extracts to approximately $100-150 \mu \mathrm{L}$.

\section{Sample analysis}

For the analysis of particle samples, the HPLC-Fluorescence technique which is a classical analytical method to quantify PAHs in environmental matrixes [37], was chosen.

Extracts were analyzed using a High Performance Liquid Chromatography system (Thermo Electron Corporation, Spectra System) equipped with a Diode Array Detector (DAD, Thermo Finnigan, Spectra System UV6000LP) and a fluorescence detector (Thermo Scientific, Finnigan Surveyor FL Plus) using the external standard method. The analytical column was a $\mathrm{C}_{18}$ Pinnacle II PAH (Restek) $150 \mathrm{~mm} \times 3.0 \mathrm{~mm} \mathrm{ID} \times 4 \mu \mathrm{m}$ (particle size). Temperature oven was set to $30^{\circ} \mathrm{C}$. Acetonitrile and water was used as mobile phase with a flow rate of $1 \mathrm{~mL} \mathrm{~min}^{-1}$. The elution gradient began with 50:50 (ACN: $\mathrm{H}_{2} \mathrm{O}$ ), then went to 60:40 (ACN: $\left.\mathrm{H}_{2} \mathrm{O}\right)$ in 7 min, then 70:30 (ACN: $\mathrm{H}_{2} \mathrm{O}$ ) until $9 \mathrm{~min}$, and linear gradient to $100 \%$ of ACN was programmed until $20 \mathrm{~min}$, with a final hold of 5 min. Initial conditions were reached in $1 \mathrm{~min}$ and maintained $5 \mathrm{~min}$ before next run. The overall run time was thus $30 \mathrm{~min}$. Before HPLC analysis, the sample was diluted in Milli-Q water so that the sample was in the initial gradient conditions (50:50/ACN: $\mathrm{H}_{2} \mathrm{O}$ ) allowing sharper peaks.

Each compound (or group of PAHs compounds) was detected at its optimum emission/excitation wavelength: 270/330 nm (NAP, ACE, FLU), 250/370 nm (PHE), 250/400 nm (ANT), 270/440 nm (FLN), 270/400 nm (PYR), 270/390 nm (B[a]A, CHR), 290/430 nm (B[b]F, $\mathrm{B}[\mathrm{k}] \mathrm{F}, \mathrm{B}[\mathrm{a}] \mathrm{P}, \mathrm{DB}[\mathrm{a}, \mathrm{h}] \mathrm{A}, \mathrm{B}[\mathrm{g}, \mathrm{h}, \mathrm{i}] \mathrm{P})$ and $305 / 500 \mathrm{~nm}$ (IND). ACY which is not fluorescent was quantified with the DAD at his optimum absorbance wavelength $\lambda=229 \mathrm{~nm}$.

\section{Results \& Discussion}




\subsection{Sample preparation}

As shown in Table 2, many literature studies related to PAHs measurements mention an extraction step (solvent volume between $2-100 \mathrm{~mL}$ ) then followed by a preliminary concentration step with rotary evaporator, then sometimes followed by a filtration and/or a purification step and finally a last concentration step (final volume in the range 10-4 000 mL) to enhance PAHs detection. Since our samples may contain small amounts of PAHs, it is essential to reduce the number of sample treatments. In addition, it is of interest to avoid large solvent volumes because they require long concentration step, which hence increase the risk of PAHs loss by evaporation during concentration step.

Three key steps of our method were evaluated separately in order to avoid any PAHs loss during the global sample preparation procedure described in Figure 2:1) the accelerated solvent extraction of PAHs from the filter; 2) the primary concentration of the extract until $1 \mathrm{~mL}$ by means of a rotary evaporator at $45^{\circ} \mathrm{C}$ and 220 mbar; 3) the final concentration of the pre-concentrated extract to about 100-150 $\mu \mathrm{L}$ under a gentle Nitrogen stream. Each recovery experiment was realized in triplicates and the error bars reported in the figures $3 \mathrm{a}, \mathrm{b}$ and $\mathrm{c}$ are the relative standard deviations.

Recovery experiments were first evaluated for the second step by adding $20 \mu \mathrm{L}$ of a solution containing $16 \mathrm{PAHs}$ at $1 \mathrm{mg} \mathrm{L}^{-1}$, i.e. $20 \mathrm{ng}$ for each PAH, in a typical volume of $70 \mathrm{~mL}$ of acetonitrile which is an estimated volume obtained after a 3 -static ASE extraction with $34 \mathrm{~mL}$ cells. The solution was then concentrated to about $1 \mathrm{~mL}$ by using a rotary evaporator at $45^{\circ} \mathrm{C}$ and $220 \mathrm{mbar}$, in order to obtain PAHs concentrations of $\sim 20 \mu \mathrm{g} \mathrm{L}^{-1}$. The extract was then diluted by a factor 2 with milli-Q water and the resulting PAHs solution of $\sim 10 \mu \mathrm{g} \mathrm{L}^{-1}$ was analyzed by HPLC. Figure 3a shows no significant PAHs loss within the experimental uncertainties during the primary concentration of the extracted solution by using a rotary evaporator.

Once this step of concentration by a rotary evaporator validated, the potential PAHs losses induced by the ASE extraction were also quantified. For this, as previously performed in other study [38], filters were spiked with $20 \mu \mathrm{L}$ of a solution containing 16 PAHs at $1 \mathrm{mg} \mathrm{L}^{-1}$, i.e. with $20 \mathrm{ng}$ of each PAH, before extraction under different ASE conditions. The extraction of blank filters spiked with certified standards was preferred instead of extracting reference materials [2,39] for the same reasons cited by Delgado-Saborit et $a l$. [38] which mentioned, first that the matrix is different between certified reference materials (powder) and particle collected onto filters and then, that a certified material is more expensive that a PAHs standard solution. Consequently, the use of a standard solution has been chosen regarding the number of tests performed to optimize the method. In order to evaluate the efficiency of extraction and finally choose optimum conditions, solvent and static time parameters were tested. Two solvents were tested, dichloromethane and acetonitrile (AcN). Static durations tested were 5 and $10 \mathrm{~min}$. The evaluation of the number of static necessary to achieve a quantitative extraction of the 16 PAHs was realized by extracting 3 consecutive times the same spiked filter, $3 \times 5$ 
min and $3 \times 10 \mathrm{~min}$, respectively. Our results show that extraction is almost quantitative after the first extraction, whatever its duration. The second static allows the collection of the rest of PAHs. The extraction yield reached about $100 \%$ whatever the ASE extraction time so that 5 min was finally chosen. Consequently, the final ASE method chosen is based on 3 static steps of $5 \mathrm{~min}$. Both solvents gave the same extraction efficiency for PAHs. However, dichloromethane contained many impurities and its use for extraction implied solvent exchange before HPLC analysis $[5,11,40]$, so that acetonitrile was finally chosen. The extract of about $70 \mathrm{~mL}$ was then concentrated to $1 \mathrm{~mL}$ using the rotary evaporator before dilution with water and HPLC analysis. Only these latter results are presented in Figure $3 b$.

The final sample concentration step was evaluated with $1 \mathrm{~mL}$ of a solution containing 16 PAHs at $10 \mu \mathrm{g} \mathrm{L}^{-1}$ introduced in a vial and evaporated under a gentle Nitrogen stream to approximately 100 $150 \mu \mathrm{L}$. The final volume was determined by weighing. This solution was diluted 10 times in a 50:50 $\mathrm{v} / \mathrm{v}_{2} \mathrm{O}$ : AcN mixture to obtain a final solution of about $10 \mu \mathrm{g} \mathrm{L}{ }^{-1}$ which was analyzed by HPLC. The results reported in Figure $3 \mathrm{c}$ highlight no significant PAHs loss during the third step.

Consequently, Figure 3 shows no significant loss within the experimental uncertainties for the 3 steps investigated. However, small losses was observed for low molecular weight PAHs, i.e. PAHs containing 2 or 3 aromatic cycles such NAP, ACY, ACE, FLU, PHE and ANT. For these PAHs, the losses reached 2-8\% for the ASE extraction and varied in the range 1-5\% for the primary concentration step with rotary evaporator although they were almost nonexistent during the final concentration step using a nitrogen stream varying in the range 2-3\%. All these steps evaluated independently show that the overall PAHs loss, even for those with a low molecular weight, should not exceed more than a few percent. The overall recovery experiments of 92-99\% obtained in this study are slightly better than most of those found in the literature: 77.6-90.3\% for NAP and DB[a,h]A with 2 ASE cycles, respectively [34], 73-88 \% for NAP and IND using ultrasonic extraction [40], 78.8-96.5 \% for NAP and PHE using ultrasonic extraction [5], 90.1-102.4 \% for 1-methylanthracene and $\mathrm{B}[\mathrm{a}] \mathrm{P}$ using also ultrasonic extraction [11], and up to $102 \%$ for $\mathrm{DB}[\mathrm{a}, \mathrm{h}] \mathrm{A}$ with Soxhlet extraction [41]. Consequently, our sample preparation including both sample extraction and its concentration before HPLC analysis are validated and can be potentially applied to air particulate samples.

\subsection{Calibrations}

For the 16 studied PAHs, calibration curves were obtained by injecting 3 times the same concentrations, each calibration curves containing between 9 and 12 points. The calibration curves (see supplementary data) were plotted in the concentrations ranges of $0.05-45 \mu \mathrm{g} \mathrm{L}^{-1}$ for the most part of PAHs or alternatively in the range of $0.1(0.5)-92 \mu \mathrm{g} \mathrm{L}^{-1}$ for PAHs exhibiting a less intense response such as NAP, ACY, DB[a,h]A and IND. Calibration curves up to $27 \mu \mathrm{g} \mathrm{L}^{-1}$ for PAHs exhibiting a high responses such as $\mathrm{B}[\mathrm{k}] \mathrm{F}$ were achieved while calibration curve for ANT was in the range $0.01-18 \mu \mathrm{g}$ 
$\mathrm{L}^{-1}$ because the response reached the saturation detector for upper concentrations. As shown in table 1, the calibrations were fully and remarkably linear $\left(R^{2}>0.999\right)$ over the entire concentrations ranges investigated for all PAHs. Linearity was here determined by plotting the linear regression of the 9-12 calibration points repeated 3 times. This good linearity $\left(\mathrm{R}^{2} \geq 0,99\right)$ was also observed within the uncertainties for concentrations lower than $2.5 \mu \mathrm{g} \mathrm{L} \mathrm{L}^{-1}$.

\subsection{Repeatability, reproducibility and Limits Of Detection and Quantification}

For each PAH and for each concentration, repeatability defined as the intra-day variation ( $\left.\mathrm{VC}_{\text {intra }}\right)$ and reproducibility defined as the inter-day variation $\left(\mathrm{VC}_{\mathrm{inter}}\right)$ for a given concentration were expressed using the variation coefficient $(\mathrm{VC}) . \mathrm{VC}_{\text {inter }}$ was determined by injecting the same concentration every week during 1 month. VC is derived by the response's standard deviation to average value ratio, converted to a percentage. $\mathrm{VC}_{\text {inter }}$, for an injected concentration of $1 \mu \mathrm{g} \mathrm{L}^{-1}$, varied between $0.8 \%$ for CHR, PHE and B[a]P and $7.3 \%$ for ACY (UV detection). The accuracy was evaluated on 3 points; each one was injected 3 times. The method is considered accurate if the recalculated concentration is between 90 and $110 \%$ of the real concentration. We just accept an accuracy of $20 \%$ for B [g,h,i]P and IND because of their less intense response due to larger peaks.

Limits of Quantification (LOQ) were derived from the Food and Drug Administration (FDA) definition [42] which define the LOQ of an individual analytical procedure as the lowest amount of analyte in a sample which can be quantitatively determined with suitable precision (VC $\leq 20 \%$ ) and accuracy (between $80 \%$ and $120 \%$ of the real concentration value). The Limit of Detection (LOD) is defined as the first point for which one of these 2 criteria is not respected. Every value was evaluated on the basis of three injections. The resulting LOQ reported in Table 1 have been converted in mass term by multiplying the injection volume (injection loop of $20 \mu \mathrm{L}$ ) to concentrations $\left(\mu \mathrm{g} \mathrm{L}^{-1}\right)$, which correspond to injected quantity between 1 and $9.4 \mathrm{pg}$. As expected, ACY which was detected by UV at $229 \mathrm{~nm}$ exhibited the worst sensitivity with 7 other PAHs measured by fluorescence, namely NAP, ACE, FLN, PYR, DB[a,h]A, B[g,h,i]P and IND. Conversely, ANT, B[k]F and B[a]P showed more intense fluorescence response and then the best sensitivy. The LOD in mass term were approximately 5 times lower than the LOQ and were in the range $0.2-2 \mathrm{pg}$ corresponding to 0.01 $0.10 \mu \mathrm{g} \mathrm{L}^{-1}$ (see Table 1). Again, our values are similar to those found in literature with LOD between 0.076-15.6 pg [11], 0.53-29.1 pg [43] or LOQ between 0.09 and $10 \mu \mathrm{g} \mathrm{L}^{-1}$ for B[a]A and ACY, respectively [14]. LOD and LOQ corresponding to airborne concentrations with a sampling volume of $20 \mathrm{~m}^{3}$ have been also derived and reported in Table 1. The comparison of these airborne concentrations with other values reported in the literature (Table 2) highlights the analytical method developed in this work presents lower LOD (in units of $\mu \mathrm{g} \cdot \mathrm{m}^{-3}$ ) if we consider all PAHs monitored. In addition, other methods that may be almost as sensitive for PAHs quantification were related to the global particulate phase or only one size fraction[11,15,44-47]. 


\subsection{Minimum air sampling volumes for PAHs collection using a 3-stages Cascade Impactor}

The goal of this work was to determine what is the minimum sampling volume needed to detect PAHs in indoor air at each collection plate of our cascade impactor.

The analytical LOQ (Table 1) of individual PAHs were then used to evaluate the sampling volume of air required to quantify particulate PAHs. Even if detection limit is a key criterion to assess the sensitivity of an analytical instrument, different approaches to evaluate this value are available and show differences. Kim and Kim [48] evaluated for several Volatile Organic Compounds both LOD (determined from three times the standard deviation of background noise $(n=7)$ ) and the Method Detection Limit (MDL) (calculated following relevant U.S. EPA Guidelines $(n=7)$ ) and show that MDL are always higher than LOD, both values being below the LOQ value. Finally, the LOQ was used instead of LOD because the objective of our study is to determine the minimum sampling volume needed to quantify PAHs in indoor air at each collection plate of the cascade impactor.

The detectable masses of PAHs were first calculated from the LOQ (in $\mu \mathrm{g} \mathrm{L}^{-1}$ ) and the final volume in the HPLC vial of $300 \mu \mathrm{L}$ (taken into account the water dilution) after the concentration steps of the sample concentration. These detectable masses (in units of ng) were then divided by the concentrations of individual PAHs (in units of $\mathrm{ng} \mathrm{m}^{-3}$ ) found in European indoor environments in

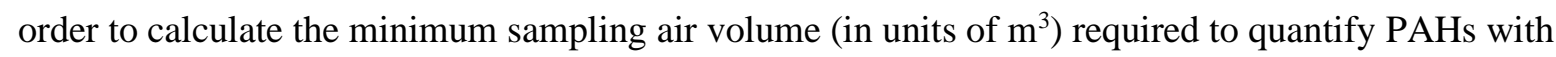
an acceptable accuracy. Several studies in Europe measured concentrations of particulate PAHs in indoor air [2,4,6,7,14,15,21-23]. Among the latter, one conducted by Delgado-Saborit et al. (2011) had a significant quantitative sample with 81 homes and 30 offices [6]. Considering the different PAHs, the geometric mean values ranged between $0.03 \mathrm{ng} \mathrm{m}^{-3}$ for DB[a,h]A and $0.36 \mathrm{ng} \mathrm{m}^{3}$ for FLN in homes (see Table 3). In addition, these values were also representative of those found elsewhere in Europe. For instance, the concentrations of $\mathrm{B}[\mathrm{a}] \mathrm{P}$ in non-smoking area were as follows (in units of ng $\mathrm{m}^{-3}$ ): 0.09 (n.d-2.40) in homes and 0.09 (n.d-1.25) in offices [6], 0.1 in a cafeteria after a smoking ban [22], $0.573(0.131-1.510)$ [14], $0.612(0.107-1.02)$ [21], between 0.09 and $0.25 \mathrm{ng} \mathrm{m}^{-3}$ in a street-side non-smoker living room [2], $0.17 \mathrm{ng} \mathrm{m}^{-3}(0.03-0.39)$ and $0.49 \mathrm{ng} \mathrm{m}^{-3}(0.15-1.12)$ in homes close to low and high-traffic density, respectively [7].

Based on these calculations and assumptions, the minimum sampling air volume in homes reported in Table 3 varies between 0.09 and $1.57 \mathrm{~m}^{3}$ except for $\mathrm{DB}[\mathrm{a}, \mathrm{h}] \mathrm{A}$ where the value reach 4.70 $\mathrm{m}^{3}$. Similarly, these calculated values are in the range $0.13-1.76 \mathrm{~m}^{3}$ for the offices, when DB[a,h]A is still excluded. These estimated sampling volume are the same order of magnitude that those used by Delgado-Saborit et al. in their study, i.e. 1.44-4.32 $\mathrm{m}^{3}[6,49]$. The calculated sampling air volume depends on the PAH and its LOQ but also on its average abundance in air. Note that these values could be $6(1 \mathrm{~mL}: 0.15 \mathrm{~mL})$ times higher if the sample is maintained to $1 \mathrm{~mL}$ prior dilution and injection. The final concentration of the pre-concentrated extract down to $150 \mu \mathrm{L}$ under a gentle Nitrogen stream is therefore an essential step which allows the reduction of the sampling volume. 
Considering the use of a 3-stages Cascade Impactor to collect simultaneously PM $>10 \mu \mathrm{m}$, $2.5 \mu \mathrm{m}<\mathrm{PM}<10 \mu \mathrm{m}, 1 \mu \mathrm{m}<\mathrm{PM}<2.5 \mu \mathrm{m}$ and $\mathrm{PM}_{<1}$ (and then to derive $\mathrm{PM}_{1}, \mathrm{PM}_{2.5}$ and $\mathrm{PM}_{10}$ ) for particulate individual PAHs quantification, it appears that the reasonable air sampling volume is one order magnitude higher than those calculated above. Consequently, 10 or $20 \mathrm{~m}^{3}$ should be enough to determine with a good accuracy the concentrations of the 16 investigated PAHs in this study. At a flow rate of $0.5 \mathrm{~m}^{3} \mathrm{~h}^{-1}$, the duration of air sampling should be in the range 20-40 hours. This sampling air volume range is between 7.5 and 90 times lower than those of $150-900 \mathrm{~m}^{3}$ recommended by Pandey et al., (2011) for PAHs sampling in outdoor air.

\section{Conclusion}

This study proposes a sensitive and efficient method for quantification of particulate PAHs in ambient air, by coupling the particulate matter collection using a 3-stages Cascade Impactor and the classic analysis by HPLC-fluorescence (or UV in the case of Acenaphtylene). The development of this analytical method, and above all the sample treatment including its concentration to $100-150 \mu \mathrm{L}$ followed by HPLC analysis, allows to quantify the 16 US-EPA PAHs related to the size particles (PM $>10 \mu \mathrm{m}, 2.5 \mu \mathrm{m}<\mathrm{PM}<10 \mu \mathrm{m}, 1 \mu \mathrm{m}<\mathrm{PM}<2.5 \mu \mathrm{m}$ and $\mathrm{PM}_{<1}$ with a sampling duration occurring for only 24 or 48 hours in relatively standard indoor environments such as homes and offices. This experimental approach allows to derive the individual $\mathrm{PAHs}$ concentrations in $\mathrm{PM}_{1}, \mathrm{PM}_{2.5}$ and $\mathrm{PM}_{10}$.

LOD and LOQ corresponding to the potential airborne concentrations (in units of $\mu \mathrm{g} \mathrm{m}^{-3}$ ) with a sampling volume of $20 \mathrm{~m}^{3}$ have been determined. These values compared to the literature ones highlight our analytical method coupling sampling, sample treatment and analysis, exhibit lower LOD.

This new sampling and analytical method has been implemented in different indoor environments and the results are detailed in another publication [33].

\section{Acknowledgment}

Financial support for this work has been provided by the French Ministry of Environment and ADEME through the PRIMEQUAL 2 program (Project MERMAID). This work was also supported by the region of Alsace and the REseau Alsace de Laboratoires en Ingénierie et Sciences pour l'Environnement (REALISE). 


\section{References}

[1] S. Orecchio, S. Cannata, L. Culotta, How building an underwater pipeline connecting Libya to Sicilian coast is affecting environment: polycyclic aromatic hydrocarbons (PAHs) in sediments; monitoring the evolution of the shore approach area of the Gulf of Gela (Italy), J. Hazard. Mater. 181 (2010) 647-658. doi:10.1016/j.jhazmat.2010.05.061.

[2] H. Fromme, T. Lahrz, M. Piloty, H. Gebhardt, A. Oddoy, H. Rüden, Polycyclic aromatic hydrocarbons inside and outside of apartments in an urban area, Sci. Total Environ. 326 (2004) 143-149. doi:10.1016/j.scitotenv.2004.02.002.

[3] L. Kliucininkas, D. Martuzevicius, E. Krugly, T. Prasauskas, V. Kauneliene, P. Molnar, et al., Indoor and outdoor concentrations of fine particles, particle-bound PAHs and volatile organic compounds in Kaunas, Lithuania, J. Environ. Monit. 13 (2011) 182-191. doi:10.1039/c0em00260g.

[4] E. Krugly, D. Martuzevicius, R. Sidaraviciute, D. Ciuzas, T. Prasauskas, V. Kauneliene, et al., Characterization of particulate and vapor phase polycyclic aromatic hydrocarbons in indoor and outdoor air of primary schools, Atmos. Environ. 82 (2014) 298-306. doi:10.1016/j.atmosenv.2013.10.042.

[5] L. Zhu, H. Lu, S. Chen, T. Amagai, Pollution level, phase distribution and source analysis of polycyclic aromatic hydrocarbons in residential air in Hangzhou, China, J. Hazard. Mater. 162 (2009) 1165-1170. doi:10.1016/j.jhazmat.2008.05.150.

[6] J.M. Delgado-Saborit, C. Stark, R.M. Harrison, Carcinogenic potential, levels and sources of polycyclic aromatic hydrocarbon mixtures in indoor and outdoor environments and their implications for air quality standards, Environ. Int. 37 (2011) 383-392. doi:10.1016/j.envint.2010.10.011.

[7] P.H. Fischer, G. Hoek, H. van Reeuwijk, D.J. Briggs, E. Lebret, J.H. van Wijnen, et al., Trafficrelated differences in outdoor and indoor concentrations of particles and volatile organic compounds in Amsterdam, Atmos. Environ. 34 (2000) 3713-3722. doi:10.1016/S13522310(00)00067-4.

[8] S.K. Pandey, K.-H. Kim, R.J.C. Brown, A review of techniques for the determination of polycyclic aromatic hydrocarbons in air, TrAC Trends Anal. Chem. 30 (2011) 1716-1739. doi:10.1016/j.trac.2011.06.017.

[9] A. Li, T.M. Schoonover, Q. Zou, F. Norlock, L.M. Conroy, P.A. Scheff, et al., Polycyclic aromatic hydrocarbons in residential air of ten Chicago area homes: Concentrations and influencing factors, Atmos. Environ. 39 (2005) 3491-3501. doi:10.1016/j.atmosenv.2005.02.029.

[10] J. Masih, A. Masih, A. Kulshrestha, R. Singhvi, A. Taneja, Characteristics of polycyclic aromatic hydrocarbons in indoor and outdoor atmosphere in the North central part of India, J. Hazard. Mater. 177 (2010) 190-198. doi:10.1016/j.jhazmat.2009.12.017.

[11] T. Ohura, T. Amagai, M. Fusaya, H. Matsushita, Polycyclic Aromatic Hydrocarbons in Indoor and Outdoor Environments and Factors Affecting Their Concentrations, Environ. Sci. Technol. 38 (2004) 77-83. doi:10.1021/es030512o.

[12] G. Buonanno, G.B. Marks, L. Morawska, Health effects of daily airborne particle dose in children: Direct association between personal dose and respiratory health effects, Environ. Pollut. 180 (2013) 246-250. doi:10.1016/j.envpol.2013.05.039.

[13] A. Zanobetti, M. Franklin, P. Koutrakis, J. Schwartz, Fine particulate air pollution and its components in association with cause-specific emergency admissions, Environ. Health. 8 (2009) 58. doi:10.1186/1476-069X-8-58.

[14] D. Castro, K. Slezakova, C. Delerue-Matos, M. da C. Alvim-Ferraz, S. Morais, M. do C. Pereira, Polycyclic aromatic hydrocarbons in gas and particulate phases of indoor environments influenced by tobacco smoke: Levels, phase distributions, and health risks, Atmos. Environ. 45 (2011) 1799-1808. doi:10.1016/j.atmosenv.2011.01.018.

[15] H. Fromme, A. Oddoy, M. Piloty, M. Krause, T. Lahrz, Polycyclic aromatic hydrocarbons (PAH) and diesel engine emission (elemental carbon) inside a car and a subway train, Sci. Total Environ. 217 (1998) 165-173. doi:10.1016/S0048-9697(98)00189-2. 
[16] K.H. Jung, M.M. Patel, K. Moors, P.L. Kinney, S.N. Chillrud, R. Whyatt, et al., Effects of heating season on residential indoor and outdoor polycyclic aromatic hydrocarbons, black carbon, and particulate matter in an urban birth cohort, Atmos. Environ. 44 (2010) 4545-4552. doi:10.1016/j.atmosenv.2010.08.024.

[17] L.-Y. Lin, I.-J. Liu, H.-C. Chuang, H.-Y. Lin, K.-J. Chuang, Size and composition effects of household particles on inflammation and endothelial dysfunction of human coronary artery endothelial cells, Atmos. Environ. 77 (2013) 490-495. doi:10.1016/j.atmosenv.2013.05.045.

[18] M. Junker, C. Monn, Particulate size distributions and pPAH - concentrations of ETS in a cafeteria before and after smoking ban, J. Aerosol Sci. 29, Supplement 1 (1998) S289-S290. doi:10.1016/S0021-8502(98)00433-9.

[19] M. Junker, T. Koller, C. Monn, An assessment of indoor air contaminants in buildings with recreational activity, Sci. Total Environ. 246 (2000) 139-152. doi:10.1016/S00489697(99)00452-0.

[20] L. Wallace, Real-Time Monitoring of Particles, PAH, and CO in an Occupied Townhouse, Appl. Occup. Environ. Hyg. 15 (2000) 39-47. doi:10.1080/104732200301836.

[21] K. Slezakova, D. Castro, M.C. Pereira, S. Morais, C. Delerue-Matos, M.C. Alvim-Ferraz, Influence of tobacco smoke on carcinogenic PAH composition in indoor PM10 and PM2.5, Atmos. Environ. 43 (2009) 6376-6382. doi:10.1016/j.atmosenv.2009.09.015.

[22] J. Pey, B.L. van Drooge, A. Ripoll, T. Moreno, J.O. Grimalt, X. Querol, et al., An evaluation of mass, number concentration, chemical composition and types of particles in a cafeteria before and after the passage of an antismoking law, Particuology. 11 (2013) 527-532. doi:10.1016/j.partic.2013.02.007.

[23] G. Sangiorgi, L. Ferrero, B.S. Ferrini, C. Lo Porto, M.G. Perrone, R. Zangrando, et al., Indoor airborne particle sources and semi-volatile partitioning effect of outdoor fine PM in offices, Atmos. Environ. 65 (2013) 205-214. doi:10.1016/j.atmosenv.2012.10.050.

[24] Y. Zhang, Indoor Air Quality Engineering, CRC Press, 2004.

[25] V.A. Marple, B.Y.H. Liu, K.T. Whitby, Fluid mechanics of the laminar flow aerosol impactor, J. Aerosol Sci. 5 (1974) 1-16. doi:10.1016/0021-8502(74)90002-0.

[26] K. Willeke, J.J. Mcfeters, The influence of flow entry and collecting surface on the impaction efficiency of inertial impactors, J. Colloid Interface Sci. 53 (1975) 121-127. doi:10.1016/00219797(75)90042-9.

[27] V.A. Marple, K. Willeke, Impactor design, Atmospheric Environ. 1967. 10 (1976) 891-896. doi:10.1016/0004-6981(76)90144-X.

[28] M. Marjamäki, J. Keskinen, D.-R. Chen, D.Y.H. Pui, Performance evaluation of the electrical low-pressure impactor (ELPI), J. Aerosol Sci. 31 (2000) 249-261. doi:10.1016/S00218502(99)00052-X.

[29] D. Boulaud, P. Gérasimo, G. Martin, L. Martinot, A. Nourreddine, J.C. Sens, Évaluation du facteur de mise en suspension de contamination dans les installations nucléaires, Radioprotection. 38 (2003) 493-508. doi:10.1051/radiopro:2003015.

[30] A.H. de Boer, D. Gjaltema, P. Hagedoorn, H.W. Frijlink, Characterization of inhalation aerosols: a critical evaluation of cascade impactor analysis and laser diffraction technique, Int. J. Pharm. 249 (2002) 219-231. doi:10.1016/S0378-5173(02)00526-4.

[31] V.A. Marple, B.Y.H. Liu, On fluid flow and aerosol impaction in inertial impactors, J. Colloid Interface Sci. 53 (1975) 31-34. doi:10.1016/0021-9797(75)90031-4.

[32] A. Robache, F. Mathé, J.C. Galloo, R. Guillermo, Multi-element analysis by inductively coupled plasma optical emission spectrometry of airborne particulate matter collected witha lowpressure cascade impactor, Analyst. 125 (2000) 1855-1859. doi:10.1039/B003048L.

[33] C. Liaud, T. Dintzer, V. Tschamber, G. Trouvé, S. Le Calvé, Application of a 3-stages Cascade Impactor air sampling method to measure Particle-bound PAHs in 8 Indoor environments: Chemical analysis of the particles and their observation using Scanning Electron Microscopy, En Correct. Dans Atmospheric Environ. (2014).

[34] J. He, R. Balasubramanian, Determination of Atmospheric Polycyclic Aromatic Hydrocarbons Using Accelerated Solvent Extraction, Anal. Lett. 42 (2009) 1603-1619. doi:10.1080/00032710902993886. 
[35] S. Percot, V. Ruban, P. Roupsard, D. Maro, M. Millet, Use of beryllium-7 as a surrogate to determine the deposition of metal and polycyclic aromatic hydrocarbon through urban aerosols in Nantes, France, Atmos. Environ. 74 (2013) 338-345. doi:10.1016/j.atmosenv.2013.03.056.

[36] P. Popp, P. Keil, M. Möder, A. Paschke, U. Thuss, Application of accelerated solvent extraction followed by gas chromatography, high-performance liquid chromatography and gas chromatography-mass spectrometry for the determination of polycyclic aromatic hydrocarbons, chlorinated pesticides and polychlorinated dibenzo-p-dioxins and dibenzofurans in solid wastes, J. Chromatogr. A. 774 (1997) 203-211. doi:10.1016/S0021-9673(97)00337-3.

[37] L.D. Gratz, S.T. Bagley, D.G. Leddy, J.H. Johnson, C. Chiu, P. Stommel, Interlaboratory comparison of HPLC-fluorescence detection and GC/MS: analysis of PAH compounds present in diesel exhaust, J. Hazard. Mater. 74 (2000) 37-46.

[38] J.M. Delgado-Saborit, N. Aquilina, S. Baker, S. Harrad, C. Meddings, R.M. Harrison, Determination of atmospheric particulate-phase polycyclic aromatic hydrocarbons from low volume air samples, Anal. Methods. 2 (2010) 231-242. doi:10.1039/B9AY00157C.

[39] S. Masala, T. Ahmed, C. Bergvall, R. Westerholm, Improved efficiency of extraction of polycyclic aromatic hydrocarbons (PAHs) from the National Institute of Standards and Technology (NIST) Standard Reference Material Diesel Particulate Matter (SRM 2975) using accelerated solvent extraction, Anal. Bioanal. Chem. 401 (2011) 3305-3315. doi:10.1007/s00216-011-5446-9.

[40] J. Cristale, F.S. Silva, G.J. Zocolo, M.R.R. Marchi, Influence of sugarcane burning on indoor/outdoor PAH air pollution in Brazil, Environ. Pollut. 169 (2012) 210-216. doi:10.1016/j.envpol.2012.03.045.

[41] Morville, Delhomme, O, Millet, M, Seasonal and diurnal variations of atmospheric PAH concentrations between rural, suburban and urban areas, Atmospheric Pollut. Res. 2 (2011) 366373.

[42] U.S. Department of Health and Human Services, Food and Drug Administration, Guidance for Industry Bioanalytical Method Validation, (2001).

[43] L. Zhu, J. Wang, Sources and patterns of polycyclic aromatic hydrocarbons pollution in kitchen air, China, Chemosphere. 50 (2003) 611-618. doi:10.1016/S0045-6535(02)00668-9.

[44] Y. Liu, L. Zhu, X. Shen, Polycyclic Aromatic Hydrocarbons (PAHs) in Indoor and Outdoor Air of Hangzhou, China, Environ. Sci. Technol. 35 (2001) 840-844. doi:10.1021/es001354t.

[45] Y.Y. Naumova, J.H. Offenberg, S.J. Eisenreich, Q. Meng, A. Polidori, B.J. Turpin, et al., Gas/particle distribution of polycyclic aromatic hydrocarbons in coupled outdoor/indoor atmospheres, Atmos. Environ. 37 (2003) 703-719. doi:10.1016/S1352-2310(02)00820-8.

[46] Y.Y. Naumova, S.J. Eisenreich, B.J. Turpin, C.P. Weisel, M.T. Morandi, S.D. Colome, et al., Polycyclic Aromatic Hydrocarbons in the Indoor and Outdoor Air of Three Cities in the U.S., Environ. Sci. Technol. 36 (2002) 2552-2559. doi:10.1021/es015727h.

[47] C.-S. Li, Y.-S. Ro, Indoor characteristics of polycyclic aromatic hydrocarbons in the urban atmosphere of Taipei, Atmos. Environ. 34 (2000) 611-620. doi:10.1016/S1352-2310(99)001715.

[48] Y.-H. Kim, K.-H. Kim, Ultimate Detectability of Volatile Organic Compounds: How Much Further Can We Reduce Their Ambient Air Sample Volumes for Analysis?, Anal. Chem. 84 (2012) 8284-8293. doi:10.1021/ac301792x.

[49] J.M. Delgado-Saborit, N.J. Aquilina, C. Meddings, S. Baker, S. Vardoulakis, R.M. Harrison, Measurement of Personal Exposure to Volatile Organic Compounds and Particle Associated PAH in Three UK Regions, Environ. Sci. Technol. 43 (2009) 4582-4588. doi:10.1021/es9005042.

[50] L. Zhu, H. Lu, S. Chen, T. Amagai, Pollution level, phase distribution and source analysis of polycyclic aromatic hydrocarbons in residential air in Hangzhou, China, J. Hazard. Mater. 162 (2009) 1165-1170. doi:10.1016/j.jhazmat.2008.05.150.

[51] A. Li, T.M. Schoonover, Q. Zou, F. Norlock, L.M. Conroy, P.A. Scheff, et al., Polycyclic aromatic hydrocarbons in residential air of ten Chicago area homes: Concentrations and influencing factors, Atmos. Environ. 39 (2005) 3491-3501. doi:10.1016/j.atmosenv.2005.02.029. 